\title{
Age-Telling in Intergenerational First-encounter Talks between College Students and Older Adults in Taiwan: A Gerontological Sociolinguistic Study
}

\author{
Chin-Hui Chen \\ Department of Modern Languages, National Pingtung University of Science and \\ Technology, Taiwan \\ E-mail: kayko1022@gmail.com \\ Yu-Ting Hong \\ Department of Modern Languages, National Pingtung University of Science and \\ Technology, Taiwan \\ E-mail: joycehong99@gmail.com \\ Yen-Ju Chen \\ Department of Modern Languages, National Pingtung University of Science and \\ Technology, Taiwan \\ E-mail: a8492a2000@gmail.com
}

Received: January 1, 2019 Accepted: January 22, 2019 Published: March 26, 2019

doi:10.5296/ijl.v11i2.14215 URL: https://https://https://doi.org/10.5296/ijl.v11i2.14215

\begin{abstract}
This study extends gerontological sociolinguistics by investigating how older Taiwanese adults disclosed their age and the relevant conversational sequences around their age-telling behaviours in first-encounter talks with college students. The 13-pair young-old conversational data were coded using Coupland, Coupland, Giles and Henwood's (1991) six age-telling strategies, and 70 age-telling utterances were identified. Frequency analysis of the age-telling utterances indicated that the older participants mostly constructed their older-age identities by referring to age-related roles and to historical changes they had witnessed.
\end{abstract}




\section{Macrothink}

International Journal of Linguistics

ISSN 1948-5425

2019, Vol. 11, No. 2

Conversation analysis suggested that both of these age-telling strategies could endow older people with greater power by casting them in roles such as information-givers or proud grandparents, and ascribe positive qualities to their age group. However, the data raised concerns that age-telling conversations could also sometimes be disenfranchising and the younger interlocutors' minimal responses to such talks were common. Wider implications of the findings for intergenerational communication are discussed in the conclusion.

Keywords: Gerontological sociolinguistics, First-encounter talks, Age-telling strategies, Intergenerational communication, Older adults 


\section{Gerontological Sociolinguistics}

As of April 2018, Taiwan's 65-plus age group constituted more than $14 \%$ of its overall population, and the country has therefore been formally recognised as an aged society (Ministry of the Interior, Taiwan, 2018). Moreover, Taiwan's proportion of older people is expected to rise further in the coming years, given increases in its population's longevity and recent sharp decreases in its birthrate. Nevertheless, language and communication studies which focused on ageing, older age or older people are still relatively rare in Taiwan, with important exceptions related to health/medical communication (Tsai, 2003, 2005, 2007, 2010, 2017, 2018), teacher-older-student communication (Chen, 2015a; Chen, 2019), in media communication (Chen, 2015b; Chen, 2015c; Chen, 2016), intergenerational first-encounter talks (Chen, 2017) and the discourse features of senior Alzheimer's patients (Lai, 2014, Lai \& Lin, 2012). Uniquely, the current study examines casual talks between younger and older adults at their first encounters, with an interest on the cultural conceptualisation of older age and the discursive management of age-telling by older people.

The research trajectory of gerontological and lifespan sociolinguistics that this study follows was pioneered by a British sociolinguist, Coupland, and his colleagues (i.e., Coupland, 1997; Coupland \& Coupland, 1993; Coupland, Coupland, \& Grainger, 1991; Coupland, Robinson, \& Coupland, 1994). Concerned with language realisations of social-ageing processes and meaning-constructions of older age in various conversational contexts, this approach regards ageing and older age as subjects to be mutually negotiated by conversational participants, and as socially and contextually sensitive notions. More specifically, Coupland and the colleagues have investigated language forms in relation to the construction of older-age identities in natural conversations (i.e., Coupland, Coupland, \& Giles, 1989; Coupland, Coupland, Giles, \& Henwood, 1991; Coupland, Coupland, \& Grainger, 1991). With the aim of extending this line of research, the present study examines age-telling management and age disclosure in natural talks between younger and older adults in Taiwan. The next section reviews the relevant prior studies on age-telling and the construction of older-age-identities in conversations.

\section{Age-telling Discourses}

\subsection{Reasons for Studying Age-Telling}

People at different points in the life cycle encounter various age-related norms and expectations, which are often culturally specific. Viewing ageing as a process rather than just a static concept (Chappel \& Orbach, 1986), studying how and when people reveal their ages can shed light on the interactional meanings of age and ageing to them and to their interlocutors.

The focus of the current study is on how older people disclose their ages and the conversational sequences in which age is made salient for interactional purposes in intergenerational-communication contexts. As argued by Coupland, Coupland and Giles (1989, p. 129), elderly people's age disclosures have significant impacts on their 'self-esteem and on cross-generational attitudes'. It is therefore worth exploring intergenerational 
conversations as loci of older people's age-telling behaviours and their younger interlocutors' responses. Moreover, because age identity can be considered a product 'of the evaluative component of our life narratives, the cumulative assessment of where we stand' (Coupland, 2001, p. 203), scholars of age-telling and other aspects of the discursive construction of older age should understand age as a social, developmental and psychological process, and clearly identify the characteristics ascribed to older age by those who disclose it (cf. Coupland, et al., 1991). In other words, studying elderly people's age-telling behaviour can enhance our understanding of social ageing.

The existing literature has identified age disclosure as prevalent in elderly people's talk, at least in Western societies (cf. Coupland, Coupland, Giles, \& Henwood, 1991; Coupland, Coupland, Giles, Henwood, \& Wiemann, 1988; Coupland et al., 1989). However, similar studies in Asian cultural contexts have been rare, with Chen (2017) representing an important exception to the rule. Helping to fill this cultural/geographic research gap is the present study's main contribution to this body of work.

Some studies have applied discourse analysis to age-telling in conversations and to the ways in which age identities are discursively managed, negotiated and constructed in interactions such as interviews and cross- or intra-generational talks (cf. Coupland, Coupland, Giles, Henwood, \& Wiemann, 1988; Coupland, Coupland \& Grainger, 1991; Jolanki, Jylhä, \& Hervonen, 2000; Nikander, 2000, 2009). The following review of the relevant studies also constitutes a clarification of the theoretical framework that guides the current study.

\subsection{Age-Telling Strategies}

The first study to focus on older people's age-disclosure strategies was conducted by Coupland, Coupland, Giles and Henwood (1991), based on a corpus of 40 cross- and within-generational conversations. It delineated two main age-marking processes: age categorisation and temporal framing. The former can occur via disclosure of one's chronological age or age-related category/role, or via the construction of age identity in terms of health, decrement or death-related topics. Temporal framing, on the other hand, is realised in terms of a past-time perspective added to current or recent topics; self-initiated association with past events/life experiences; and/or reference to historical/cultural changes. Frequency analysis of the data in Coupland et al.'s above-mentioned study indicated that the notion of elderliness is more often produced and modified in intergenerational contexts by the elderly than by their younger conversational partners. The authors argued that the encoding of age identities is a relational process and the interactional functions of age-telling could differ across peer-elderly and young-old encounters. For example, in peer-elderly encounters, age-telling could offer older people a chance to compete with each other in terms of their relative life positions and therefore, mutual and reciprocal appraisals of life statuses would likely be observed. Young-old encounters, in contrast, are marked by more ritualistic and predictable sequences involving compliment-giving by younger to older people, or expressions of surprise or disbelief as responses to elderly people's age-telling utterances. Coupland et al. also argued that their older participants' reflections on change (considered as an age-telling strategy) could render it difficult for their young interlocutors to share or match 
their narratives of historical experiences and therefore, that this strategy could impede satisfying intergenerational communication.

Coupland et al. (1989) investigated disclosures of chronological ages (DCAs) in relation to face implications and the social attitudes projected in the process of constructing age identities. Based on a corpus of 40 videotaped introductory chats between pairs of elderly and young women, and a set of complementary data including interviews with 40 elderly people aimed at eliciting their healthcare experiences, its findings suggested that intergenerational conversation was the preferred context for DCAs, which were initiated more by older than younger adults. The authors also maintained that in older people's age-telling utterances, two underlying dimensions could be found: an evaluative dimension, reflective of the positive-negative self-appraisal of one's contextual ageing; and an intersecting dimension, showing the perceived congruence and incongruence between chronological age and contextual age. This interpretive framework yielded four age-telling patterns, namely, 'Accounting DCAs', 'Disjunctive DCAs', 'DCA unlikely' and 'DCA is highly unlikely' (Coupland et al. 1989, p. 139). Their qualitative analysis also suggested that many DCAs in the interaction data reflected a normative view of older age as decremental (Accounting DCAs), but there were also DCAs that highlighted perceived discrepancies between positive contextual age and older age. No examples of the other two theorised types of DCAs were identified in the data.

In addition to the above studies, all of which were conducted in the UK, research on age-identity construction in conversations has also been conducted in other cultural contexts. For instance, Charalambidou's (2011) investigation of the conversations of Greek Cypriot females aged 62-79 revealed that these women often chose to distance themselves from the negative attributes associated with old age, despite accepting their chronological age. Similarly, Jolanki, Jylhä, and Hervonen's (2000) discourse analysis of interviews with Finnish people aged 90 and older revealed two contrasting repertoires of age talk: that is, to view older age as a choice, which usually entails positive accounts of older age, or as necessity, which instead defines it as deterioration.

Though also based on interview data, Nikander's (2009) study instead focused on how 22 Finnish baby boomers discursively managed the notions of future change and continuity. The findings revealed that these older people relied on a 'provisional continuity device' (Nikander, 2009, p. 863) to enable them to simultaneously acknowledge and distance themselves from potential lifespan changes. Nikander identified a three-step 'A, B, but A' formulation (p. 872) in older people's talk about the notions of continuity and change in decrement. The first step, A, is to downplay the significance of ageing to one's personal identity (i.e., claiming nothing has changed), followed by step $\mathrm{B}$, which softens the previous claim by acknowledging the possibility of changes occurring (e.g., admitting that little by little, our energy might decline); and lastly, a second step A, reiterating the first claim (e.g., emphasising that the speaker does not yet see that problem as affecting him/her personally).

Like Coupland et al.'s (1991), Chen's (2017) study collected first-encounter talks between younger and older people; however, these were examined in terms of the conversational 
patterns manifested in five-pair intergenerational communication in Taiwan. Much as in the above-reviewed Western research, older adults were more likely than their younger interlocutors to initiate DCAs, with the latter's predictable adjacent moves again including expressions of surprise and positive comments about the revealed older ages. However, Chen identified some conversational features that have not been discussed above, such as interview-like opening strategies, a reflection of older people's greater power to license younger interlocutors' raising of questions. Moreover, more effort to attend to language politeness could be found on the part of the younger adults, whose communication needs were often underaccommodated by their elder counterparts. Chen also discussed painful self-disclosure, observing how overwhelmed younger adults were by older people's painful disclosure of ailments and reference to death, and how the former's responses tended to consist of simple pacification, indicating their mental distance from ageing. Up to a point, then, Chen's study can be regarded as a pilot study for the present one. However, the current research will focus only on older people's age-telling behaviours, categorising them typologically and discussing some of the relevant responses, along with the social attitudes that may be reflected in the conversational sequences around DCAs.

\subsection{Research Gaps and Research Questions}

Coupland et al.'s (1991) typology of six age-telling processes illuminates the present research in two ways. First, it constitutes a clear theoretical model for the coding of age-telling behaviours and the analysis of the frequency patterns could clarify older Taiwanese people's preferences regarding age-telling strategies. Second, it could shed new light on the sequences whereby younger Taiwanese people respond to each type of their older interlocutors' age-telling strategies, thus further extending our understanding of DCAs beyond the almost exclusively Western contexts that have hitherto been studied.

In sum, elderly people's self-disclosures regarding age and ageing are deemed in this study as interactional and intergroup phenomena (see also Coupland, Coupland, Giles, \& Henwood, 1988). Therefore, this paper will explore the age-telling strategies and disclosure sequences involved in intergenerational encounters via a corpus of audio-recorded conversational data. It will be guided by the following research questions:

RQ1: How do older people discuss their ages in conversations with younger adults in Taiwan?

RQ2: What age-disclosure strategies and corresponding response sequences can be identified in conversations that feature older Taiwanese people's age-telling?

\section{Methodology}

\subsection{Data and Participants}

The data for the present study comprised 13 two-person intergenerational conversations collected in Pingtung County, Taiwan. The participants were 13 college students (four males and nine females, aged between 20-23) and 13 older local residents (nine males and four females, aged between 65-75) who were randomly paired up to converse. The college 
students, all of whom studied in the university where the lead author works, volunteered to participate in the study. The older participants were approached via the headman of a village in Pingtung County who had been offering his office as a site for older people living nearby to chat with their friends on almost a daily basis. All participants were given a consent form to sign before the recording of the talks commenced, and confirmed their agreement with the use of their conversations for research. The venue selected for data collection was the headman's office, because the older participants already felt comfortable engaging in social interaction with others there, and it was expected that they would behave more naturally in that setting and chat freely. No constraints were placed on conversational topics; the only fixed requirement was that each conversation continued for at least 10 minutes. The aggregate length of the recorded conversations was 267 minutes, and they were transcribed in Chinese for further analysis, but are presented in English translation below.

\subsection{Research Methods}

Frequency analysis was employed to answer RQ1, by establishing the relative salience of the six types of age-telling strategy (DCA; age-related category/role reference; age identity in relation to health, decrement and death; adding past-time perspective to current or recent-past status/topics; self-association with the past; and recognising historical/cultural/social change). Then, to answer RQ2, conversation analysis (Sacks, 1995) - with a focus on the interactive nature of talk about older people's age disclosure and their younger interlocutors' responses was utilised to reveal the interactional patterns in the associated conversational sequences, and to observe how older-age identity construction was mutually negotiated for immediate communication purposes.

\section{Findings}

\subsection{Distribution of Age-Telling Strategies}

As can be seen from Table 1, 70 occurrences of age-telling were identified in the data, all of which were initiated by older people. In terms of processing categories, $56 \%$ of these occurrences were age categorisation, and the remainder, temporal framing. Among the six subtypes of age-telling strategies, the most frequently employed was 'age-related category and role reference' (36\%), followed by 'recognising historical/cultural/social change' (24\%), 'self-association with the past' (16\%), and 'age identity in relation to health, decrement and death' (13\%). The least popular age-telling strategies were 'disclosure of chronological age’ (7\%) and 'adding past-time perspective to current or recent-past status/topics' (4\%). Qualitative interpretations of these results, along with the distributional patterns of the use of the six age-telling strategies, will be presented in the following section.

Table 1. Distribution of older people’s age-telling by strategy

\begin{tabular}{lllll}
\hline \multicolumn{2}{c}{ Age-telling Categories } & N & $\%$ & Subtotal \\
\hline $\begin{array}{l}\text { Age-categorisation } \\
\text { Processes }\end{array}$ & Disclosure of chronological age & 5 & $7 \%$ & \\
& Age-related category/role reference & 25 & $36 \%$ & $56 \%$ \\
\hline
\end{tabular}




\begin{tabular}{lllll}
\hline & $\begin{array}{l}\text { Age identity in relation to health, } \\
\text { decrement and death }\end{array}$ & 9 & $13 \%$ \\
& $\begin{array}{l}\text { Adding past-time perspective to } \\
\text { current or recent-past status/topics }\end{array}$ & 3 & $4 \%$ & \\
Temporal-framing & $\begin{array}{l}\text { Self-association with the past } \\
\text { Processes }\end{array}$ & 11 & $16 \%$ & $44 \%$ \\
& $\begin{array}{l}\text { Recognising } \\
\text { historical/cultural/social change } \\
\quad \text { Total }\end{array}$ & 17 & $24 \%$ & $100 \%$ \\
\hline
\end{tabular}

\subsection{Age-Identity Construction as Managed and Negotiated in Conversations}

\subsubsection{Age-Related Category/Role Reference}

As noted earlier, the most popular age-telling strategy among this study's participants was 'age-related category/role reference' ( $\mathrm{N}=25,36 \%)$. Breaking this category down further, three-fifths of those who adopted it chose to identify themselves as 'being old/older person' $(\mathrm{N}=15)$, and the remainder as occupying specific roles, i.e., grandparents $(\mathrm{N}=5)$ or retirees $(\mathrm{N}=5)$.

The wider conversational sequences corresponding to this age-telling strategy should raise concerns, given how in 11 of 15 cases, they appeared to reflect the older participants' disenfranchisement and broadly negative orientations towards older age. For example, OA3 referred to his being older as an explanation for his declining health ('we older people do not have good health', in line 2, Extract 1), and other older participants made similar remarks about age-based life constraints (e.g., 'we older people have nowhere to go', in line 4, Extract 2; lines 3-4, Extract 3; and lines 4-8, Extract 4).

\section{Extract 1}

1 OA3: I come out here to make friends. You see (.) everyone here is the same, spending

2 every day like this. We older people do not have good health

3 YA3: It is better to have something to do. [Like my mother, she

4 OA3:

[Sometimes, I stay at home and farm some land at

5 the back of my house

\section{Extract 2}

1 YA11: Do you come here every day for tea?

2 OA11: Yes I come here quite often, almost every day.

3 YA11: Every day?

4 OA11: Because I live nearby. We older people have nowhere to go so we come here to

5 find many older residents to make friends and chat.

\section{Extract 3}

1 OA4: I grow vegetables. 
2 YA4: It's good to have some harvest.

3 OA4: My life now is quite plain. Being an older person, I might just go to the farmland in

4 the morning and when the sun is too hot, it is time to go home for lunch.

\section{Extract 4}

1 OA1: I always get up at six and change my clothes before ten. After washing my face and

2 going to the toilet, I go out for a half-hour walk.

3 YA1: So early?

4 OA1: We older people don't sleep long, getting up at three and if it is still too early, we

5 continue the rest until four. My husband gets up even earlier, leaving home at five

6 every morning. I wake up after he leaves home every morning. He is off for his

7 activity and I attend to mine. He goes to his friends' places for tea and chatting. When

8 he arrives home, he always starts by putting the kettle on for tea.

In contrast to those who stigmatised older age in terms of health decrement or life constraints, those older participants who positioned themselves in relation to grandparenthood were more likely to ascribe positive qualities to their age and to express happiness and pride. This is particularly obvious from Extract 5, in which OA11 positions himself as a grandfather and reports the achievements of his grandchildren. Interestingly, such utterances were self-initiated by OA11 and appeared to be conversational moves or answers incoherent with the questions/topics raised by his younger interlocutor in the preceding turns. For example, when asked directly how old his grandchildren were (line 2, Extract 5) or if he treated his granddaughters particularly well (line 9, Extract 5), OA11 answered with irrelevant information about his granddaughters' profession and studies as nurses (lines 3-4 and 10-11, Extract 5). OA11 continued to indulge himself in reporting on his grandchildren until his younger interlocutor (YA11) rephrased the question again ('So do you care about them?', line 12, Extract 5) and finally elicited a relevant answer ('yes', line 13, Extract 5).

OA11's active effort to portray his successful grandparental role relied on emphasis of his offspring's achievements, which he presumed would be socially acknowledged. Nevertheless, he gave scant consideration to whether such conversational moves would be considered coherent in the ongoing conversation. Presumably, he expected that his younger interlocutor would provide some positive comments (e.g., 'nursing is very good', line 5 in Extract 5) as appropriate adjacent sequences to his own endeavour to construct an older-age identity via self-positioning as a proud and perhaps also a successful grandparent.

\section{Extract 5}

1 OA11: I live with my wife, my son, daughter-in-law and grandchildren.

2 YA11: Oh! You have grandchildren? How old are they?

3 OA11: My granddaughter just graduated from her college and she is still looking for a job.

She majors in nursing. 
5 YA11: Nursing is very good. I bet she can find a job very soon.

6 OA11: I think so, and my youngest granddaughter is a nurse, too.

7 YA11: So they are the same.

8 OA11: I have two granddaughters and one grandson.

9 YA11: So would you treat granddaughters particularly well?

10 OA11: Well, granddaughters (.) both of them studied in the nursing department and one

11 has a university degree and the other one only has a junior college degree.

12 YA11: So do you care about them?

13 OA11: Yes.

\subsubsection{Recognising Historical/Cultural/Social Change}

The participants' second most favoured age-telling strategy, recognising historical/cultural/social change, was used 17 times (24\%). Of these, 14 occurrences consisted of comparisons between the past and the present that included evaluations or preferences, of which 10 characterised the past as better than the present, and the other four, the present as better than the past.

Pointing out social change positions an older person in the role of information-giver, passing on knowledge or wisdom that his or her young interlocutor is assumed to lack. Older people, in this age-telling process, might be able to strategically empower themselves based on the knowledge shared in talk or through educating younger interlocutors with a tone of moral authority. In Extract 6, OA8 - who used to be a teacher (line 1) - shared his views on differences in students' behaviours between the past and the present in terms of the degree of respect and appreciation shown towards teachers (lines 3-6). YA8 was simultaneously classified into another social group, that is, 'present students', when OA8 accused them of being less respectful and grateful than their counterparts of earlier generations. This could have threatened YA8's positive face (i.e., the desire to be liked and accepted; Brown \& Levinson, 1987) and compromised his positive identification with his own age group or student identity. As can be observed in lines 7 ('I see'), 9 ('It seems to be the case') and 12 ('Indeed'), YA8 did not provide very constructive feedback on this topic, responding only with rather short acknowledgements.

\section{Extract 6}

1 YA8: Since you are a teacher, is there any student who made you impressed after so many

2 years?

3 OA8: There are some, for instance, one who retired just recently from the Taipei

4 government. But I have to say students in the past, no matter how badly behaved

5 they were, they would never beat their teachers when being punished. But, students 


\section{1) Macrothink}

International Journal of Linguistics

ISSN 1948-5425

2019, Vol. 11, No. 2

6 now instead fight back and beat their teachers if being punished. Such a big contrast!

7 YA8: I see.

8 OA8: There is no respect to teachers from present students and their parents.

9 YA8: It seems to be the case.

10 OA8: People in the past followed moral codes more strictly, knowing sense of propriety, 11 justice, honesty and honour, unlike your generation.

12 YA8: Indeed, so different now.

In Extract 7, OA2 constructed his older-age identity by associating himself with a past living environment that he deemed better than that of the present (lines 2-7, Extract 7). This arguably could have enhanced his self-esteem by eliciting positive identification ('I really envy you', line 11, Extract 7) from his younger conversational partner. In other words, this age-telling strategy potentially allows older people to negotiate a more positive image of their generation among members of other generations.

\section{Extract 7}

1 YA2: I am allergic to air pollution so I need to wear a mask when I am in Kaohsiung.

2 OA2: That is because the green land is getting less and less now. In the past, we used to

3 have a house there and there was a lot of farmland there. The air was so cool and

4 there was no need to use air conditioning because the natural wind could flow

5 through bamboo trees that could work as filters to produce fresh air. Besides, dust

6 would also attach to the bamboo tress that fell on the ground so you would not see

7 dusty wind back then, unlike now.

8 YA2: Really! I have never experienced being in a bamboo forest.

9 OA2: I really missed the time playing in the bamboo forest. We could just have a nap under

10 the trees or read novels in the cool shadows.

11 YA2: I really envy you.

\subsubsection{Self-Association with the Past}

The strategy of self-association with the past ranked third $(\mathrm{N}=11,16 \%)$ among the age-telling strategies utilised by the older adult participants. Those who employed it usually mentioned their own past life experiences, such as places they had visited, their career struggles and achievements, and so on. Unlike talk about social change, older people's age-telling via self-association with positive past life experiences did not include comparative evaluation of past and present events. Most of the reminiscences in this category were positive in nature, with a high proportion being either about the speakers' own past achievements, or about more 
general features of the past that they expected younger people not to know. As such, it is not especially surprising that more follow-up questions regarding the topics raised by older people were asked by their younger interlocutors (see, for instance, line 3, Extract 8 and line 3, Extract 9), whereas simple, short acknowledgements and other minimal responses were relatively less common (see Chen, 2017).

\section{Extract 8}

1 OA11: In the past, the time when people worked in the agricultural sector, we had a

2 hard time making a living.

3 YA11: What did you grow, grandpa?

4 OA11: I grew rice.

\section{Extract 9}

1 OA12: Fifty years ago, when I was a junior high student, I watched movies like

2 Cleopatra or 007 agents and also Japanese dramas.

3 YA12: Do recently released movies attract you?

4 OA12: I don’t watch modern movies except those adapted from old movies.

\subsubsection{Age Identity in Relation to Health, Decrement and Death}

When the older adults in the sample constructed their older-age identities in relation to health, decrement or death $(\mathrm{N}=9$; $13 \%$ of all age-telling utterances), most of the resulting conversations were negative in nature. Notably, however, the death element of this general category was not reflected in any of the nine relevant utterances, which might reflect the Taiwanese tendency to regard death as a taboo. In section 4.2.1, it was mentioned that older people sometimes categorised themselves as older and simultaneously equated this social identity with decline in health. Such age-telling behaviours are discussed in more depth below.

In two-thirds $(\mathrm{N}=6)$ of the conversational sequences involving age disclosure with health and decrement, the older adults received minimal responses from their younger interlocutors, indicating the latter's difficulties in dealing with such topics when talking with older people (see also Chen, 2017). In Extract 10, the younger adult (YA8) gave a short acknowledgement in the form of a question ('Is it?', line 2) as a response to the health complaint from his older interlocutor ('My health is not good, suffering', line 1). YA8's move, subsequent to OA8's further reinforcement of his physical problems ('I have a lot of pain' and 'watching TV is also painful', in lines 3-4, Extract 10), was to promptly direct the discussion towards another topic, that is, social gathering ('Do you older people gather here to meet friends?', line 5) rather than providing direct feedback to OA8's narratives of suffering poor health.

\section{Extract 10}

1 OA8: I think my life is too long. My health is not good, suffering. 


\section{MlMacrothink}

2 YA8: Is it?

3 OA8: I have a lot of pain. Now I can’t see you clearly. Reading newspapers and watching

$4 \quad$ TV is also painful because of my poor eyesight.

5 YA8: Do you older people gather here to meet friends?

Similarly, in Extract 11, OA1's lengthy trouble talk (lines 2-7) about surgeries and poor health was self-initiated and appeared to be irrelevant to the question previously raised by YA1 about entertainment ('Do you sing in the community centre?', line 1). Following a lengthy report of OA1's health problems, YA1 gave a minimal response ('Indeed', line 8) that served chiefly to interrupt the completion of OA1's age-telling utterance and surgery details. Due to that interruption, the conversation turned to another topic, medical advancements (line 9). This part of the interaction suggested the younger participant's lack of interest in health-in-ageing topics, even though the older interlocutor appeared to be relatively proactive about sharing his own painful experience.

Extract 11

1 YA1: Do you sing in the community centre?

2 OA1: I don't sing. In the past, I felt sorry for myself. I had a surgery on my thyroid,

3 which could have caused damage to the throat and my voice. But, luckily, I still

4 have my voice. I also had a surgery on both my feet so I have a disability card,

5 allowing me to buy tickets at half price. That was already 10 years ago. I used to

6 climb mountains when I was younger but I can't do that now. The doctors

7 advised me not to, and we need to take care of our feet. Before the [surgeries

8 YA1: [Indeed

9 OA1: Well the medical science is very advanced now, and I will go see doctors when I

10 don’t feel well.

\subsubsection{Disclosure of Chronological Age}

The older adults in the sample rarely disclosed their chronological ages when talking with younger strangers $(\mathrm{N}=5,7 \%)$. Those who did seemed to use DCA as a basis or starting point for self-evaluations, which often incorporated age-related stereotypes. Most $(\mathrm{N}=4)$ embodied what Coupland et al. (1989) described as Accounting DCAs (see, for instance, Extract 12), while only one was a Disjunctive DCA (Extract 13).

Taking Extract 12 as an example of the Accounting DCAs in the data, OA7's report of her daily activities comprised descriptions of routines such as meeting friends in the morning, returning home for lunch or taking a nap in the afternoon (lines 2-3). In the following move, her younger interlocutor, YA7, reoriented the talk from a routine-based one towards fun and 
adventure ('go out for fun' and 'go somewhere else', both in line 4), perhaps wishing to provide a different perspective on later life for the older interlocutor to take. However, by disclosing her chronological age ('being 80 years old', line 5) and self-defining as a very old person ('now I am so old', line 5), OA7 declined the offered alternative subject position and instead expressed doubt about it ('where would I go?', line 5). This use of age as a constraint was further reinforced by OA7's utterances about her sons' concerns over her safety (lines 7-9). YA7 challenged the position that underlay OA7's DCA ('Being 80 years old, you could enjoy your life', line 6), but this approach did not succeed. Through their interaction, individuals from two different generations negotiated multiple and varying age identities, but at least in this case, the older person's attitude of self-disenfranchisement did not seem to be not easily changed.

\section{Extract 12}

1 YA7: What do you do every day?

2 OA7: I come out here to chat with my friends. My husband is the head of the club for the

3 seniors. We go back home at lunchtime and take a nap in the afternoon.

4 YA7: So you don't go out for fun or go somewhere else?

5 OA7: Now I am so old. Being 80 years old, where would I go?

6 YA7: Being 80 years old, you could enjoy your life.

7 OA7: Otherwise, I would ride a bicycle for fun but my sons would say no and ask me to

8 stay at home and not go out. They think I am safer at home and they don't need to

9 worry about me.

One exceptional case, in which age was not used to justify constraints or problems in later life, can be seen in Extract 13, where OA10 reported his age to be 'just' 60 (line 2). This was primarily disclosed as a reference point for an exploration of later life characterised by playing and having fun, themes that were emphasised via repetition three times in one turn ('having fun', line 3; 'I can play', line 4; 'I can seek some fun', line 5). This made it clear that OA10's self-image was as a so-called golden ager: enjoying life, financially independent, and socially active (see Hummert, 1990; Hummert et al. 1994) and indeed energetic, as put by YA10 in line 6.

\section{Extract 13}

1 YA10: What have you been doing since retirement?

2 OA10: I have a farm so I work on the farm. Because I am just 60 years old, I'm eligible to

3 have fun in every way, and have some savings to support me. I inherited houses from 4 my parents so I have money. That is why I can play and with money, I can enjoy life.

$5 \quad$ I also invest in houses and receive rental fees, so I can seek some fun.

6 YA10: You are full of energy!

In this relatively atypical case, DCA was not merely an act of giving information about one's age but also as a stimulus to elicit more positive evaluations from the younger interlocutor regarding one's age-related status. It also works to facilitate the reinforcement of one's 
positive identification with older age. The satisfaction of such a communicative purpose, however, can only be achieved mutually: i.e., is critically dependent upon the younger conversational partner's sensitivity to the older one's social-psychological needs.

\subsubsection{Adding Past-Time Perspectives to Current or Recent-Past Status/Topics}

Very few examples of adding past-time perspectives to current or recent-past status were found $(\mathrm{N}=3,4 \%)$, and those that did occur were generally coupled with comments on health issues, e.g., 'I have diabetes, for more than 10 years, like, more than 15 or 16 years'. This strategy was also usually accompanied by the construction of age identity 'in relation to health, decrement and death' (see section 4.2.4). It could be that older adults used this strategy to reinforce the extent of their suffering from health problems so that younger adults could understand how they felt, and perhaps, offer more comforting feedback during health-in-ageing conversations.

\section{Discussion and Conclusion}

The present study's examination of older Taiwanese people's age-telling behaviours in conversations with younger adults has indicated that such behaviours mainly consisted of references to age-related roles or to historical/social changes that helped the older participants define their own generations as different from those of their younger interlocutors. Claiming to be old was the most common means of constructing older-age identity. Such age-telling talk tended to demonstrate older people's negative age-related stereotypes and self-fulfilling views about the age-based constraints they faced (see 'Accounting DCAs in Coupland et al., 1989). Such self-disenfranchising stances could pose a considerable obstacle to satisfactory intergenerational communication, especially given that younger interlocutors' attempts to challenge such a stance can easily fail (see Extract 12). Moreover, the data showed that most of the younger participants' responses to the older ones' Accounting DCAs were not sufficiently accommodative to the latter's needs to share painful experiences. Insofar as older people's painful self-disclosures probably function to relieve stress and/or to elicit comfort from others, it was discouraging that the younger adults in the sample either gave minimal responses to such disclosures, or interrupted to stop them. This area of underaccommodation in intergenerational talks in Taiwan should be the subject of additional research.

Rather than adopting the self-disfranchising attitude manifested in the most common forms of age-telling, certain older people in the sample chose to define themselves as grandparents, and successfully negotiated more positive self-images via the ensuing conversations. As mentioned previously, older people's DCAs can have impacts on their self-esteem (Coupland et al., 1988). When older people position themselves conversationally as grandparents to construct their age-identities, their interlocutors may need to support this on the level of manners, e.g., by allowing them to self-initiate such talk and express their pride in their families until satisfied, regardless of any inconsistencies between such utterances and those that preceded them (as can be seen in Extract 5). If this were done consistently, age-disclosure could arguably help enhance older people's self-esteem, especially if their interlocutors provided complimentary feedback. 
Identifying past-present differences also emerged as a popular and effective way for the older participants to differentiate their generations from those of their younger conversational partners. However, the data indicate that it also created a risk of problematic intergenerational communication, especially when the talk comprised negative evaluations of social groups that those younger interlocutors personally identified with (see Extract 6). Another potential pitfall of talk about social change is the educative tone that older people often adopt, especially while passing on moral codes such as 'students should respect teachers'. This might lead younger people to feel coerced and unable to propose a contradictory view, given that Taiwanese cultural norms (due to the influence of the Confucian tradition) require them to show respect to their elders by listening rather than arguing against what they say. However, if both parties' face is maintained in an atmosphere of mutual respect, positive intergenerational communication can arise even from older people's reminiscences about a past they perceive to be better than the present (see Extracts 8 and 9).

The main contribution of this study is that it provides a culturally (Taiwan) as well as contextually (first-encounter) specific micro-interpretation of older people's age-telling in conversation with younger adults. As such, it extends the existing body of research on this topic, which has mainly been conducted in Western societies. It also sheds some light on how age-telling can serve as a site for negotiation of one's facework, and on why intergenerational communication can be problematic (e.g., through the reinforcement of negative stereotypes of older age, including by older people themselves). In other words, ageing is an inevitable process of life, but when older adults' health-in-ageing talk stigmatises older age in line with negative stereotypes, it can arouse fear of ageing in their younger conversational partners, and thus add to the social distance between the parties.

Some limitations of the present research should also be noted. First, its small sample size of 13 older adults and 13 college students mean that its generalisability (especially from the frequency analysis of age-telling patterns) can be enhanced in future research advised to collect a bigger size of samples of young-old conversations. Second, the older participants were all from rural Pingtung County and might not be representative of the older population of Taiwan. Given the above limitations, future research could recruit more participants, including urban dwellers, and perhaps middle-aged people as a check on whether lesser age differences generate different patterns of age-telling.

\section{Acknowledgements}

This research was supported by the Ministry of Science and Technology of Taiwan under the grant number MOST106-2410-H-020-004.

\section{References}

Brown, P., \& Levinson, S. C. (1987). Politeness: Some universals in language usage. Cambridge: Cambridge University Press.

Chappell, N. L., \& Orbach, H. L. (1986). Socialisation in old age: A Meadian perspective. In V. W. Marshall (Ed.), Later life: The social psychology of ageing (pp. 75-106). London: Sage. 


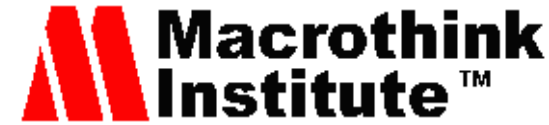

International Journal of Linguistics ISSN 1948-5425 2019, Vol. 11, No. 2

Charalambidou, A. (2011). Language and the ageing self: A social interactional approach to identity constructions of Greek Cypriot older women (Unpublished Ph.D. thesis). London: King's College.

Chen, C.-H. (2015a). Exploring gerontological sociolinguistics in senior educational contexts: age telling strategies and communication with elderly learners. Journal of Gerontology and Service Management, 3(1), 21-34. https://doi.org/10.6283/JOCSG.2015.3.1.21

Chen, C.-H. (2015b). Older adults as discursively constructed in Taiwanese newspapers: a critical discourse analysis. International Journal of Society, Culture \& Language, 3(2), 72-84.

Chen, C.-H. (2015c). Advertising Representations of Older People in the UK and Taiwan: A Comparative Analysis. International Journal of Aging and Human Development, 80(2), 140-183. https://doi.org/10.1177/0091415015590305

Chen, C.-H. (2016). Marketing discourses of aging: Critical discourse analysis of TV advertising for over-50s life insurance in Taiwan. Language, Discourse \& Society, 4(1), 7-30.

Chen, C.-H. (2017). First-encounter talks between younger and older adults in Taiwan: A conversation analysis approach. International Journal of Society, Culture \& Language, 5(2), 91-104.

Chen, C.-H. (2019). Exploring teacher-student communication in senior-education contexts in Taiwan: A communication accommodation approach. International Journal of Ageing and Later Life, Advance access, doi: 10.3384/ijal.1652-8670.17369

Coupland, J., Coupland, N., \& Grainger, K. (1991). Intergenerational discourse: Contextual versions of ageing and elderliness. Ageing \& Society, 11(2), 189-208. https://doi.org/10.1017/s0144686x00004001

Coupland, J., Coupland, N., Giles, H., \& Henwood, K. (1991). Formulating age: Dimensions of age identity in elderly talk. Discourse Processes, 14(1), 87-106. https://doi.org/10.1080/01638539109544776

Coupland, J., Robinson, J., \& Coupland, N. (1994). Frame negotiation in doctor-elderly patient consultations. Discourse \& $\quad$ Society, 5(1), $\quad$ 89-124. https://doi.org/10.1177/0957926594005001005

Coupland, N. \& Coupland, J. (1993). Discourses of ageism and anti-ageism. Journal of Aging Studies, 7(3), 279-301. https://doi.org/10.1016/0890-4065(93)90016-d

Coupland, N. (1997). Language, ageing and ageism: A project for applied linguistics? International Journal of Applied Linguistics, 7(1), 26-48. https://doi.org/10.1111/j.1473-4192.1997.tb00102.x

Coupland, N. (2014). Age in social and sociolinguistic theory. In N. Coupland, S. Sarangi, \& C. N. Candlin, (Eds.), Sociolinguistics and social theory (pp. 185-211). London: 
Routledge.

Coupland, N., Coupland, J., \& Giles, H. (1989). Telling age in later life: Identity and face implications. Text, 9(2), 129-151. https://doi.org/10.1515/text.1.1989.9.2.129

Coupland, N., Coupland, J., Giles, H., \& Henwood, K. (1988). Accommodating the elderly: Invoking and extending a theory. Language in Society, 17(1), 1-41. https://doi.org/10.1017/s0047404500012574

Coupland, N., Coupland, J., Giles, H., Henwood, K., \& Wiemann, J. (1988). Elderly self-disclosure: Interactional and intergroup issues. Language \& Communication, 8(2), 109-133. https://doi.org/10.1016/0271-5309(88)90010-9

Hummert, M. L. (1990). Multiple stereotypes of elderly and young adults: A comparison of structure and evaluations. Psychology and Aging, 5, 182-193. https://doi.org/10.1037//0882-7974.5.2.182

Hummert, M. L., Garstka, T. A., Shaner, J. L., \& Strahm, S. (1994). Stereotypes of the elderly held by young, middle-aged, and elderly adults. Journal of Gerontology: Psychological Science, 49(5), 240-249. https://doi.org/10.1093/geronj/49.5.p240

Jolanki, O., Jylhä, M., \& Hervonen, A. (2000). Old age as a choice and as a necessity: Two interpretative repertoires. Journal of Aging Studies, 14(4), 359-372. https://doi.org/10.1016/s0890-4065(00)80002-x

Lai, Y.-H. \& Lin, Y.-T. (2012). Discourse markers produced by Chinese-speaking seniors with and without Alzheimer's disease. Journal of Pragmatics, 44, 1982-2003. https://doi.org/10.1016/j.pragma.2012.09.002

Lai, Y.-H. (2014). Discourse features of Chinese-speaking seniors with and without Alzheimer's disease. Language and Linguistics, 15(3) 411-434. https://doi.org/10.1177/1606822x14520665

Ministry of the Interior, Taiwan (2018). The population statistics for week 15 in 2018. Retrieved from https://www.moi.gov.tw/files/site_node_file/7635/week10715.pdf.

Nikander, P. (2000). 'Old' versus 'little girl': A discursive approach to age categorization and morality. Journal of Aging Studies, 14(4), 335-358. https://doi.org/10.1016/s0890-4065(00)80001-8

Nikander, P. (2009). Doing change and continuity: Age identity and the micro-macro divide. Ageing \& Society, 29(6), 863-881. https://doi.org/10.1017/s0144686x09008873

Sacks, H. (1995). Lectures on conversation. Oxford: Blackwell.

Tsai, M. H. (2018). 'That's exactly what I will share with you today!' Negotiation for a ticket of entry to unsolicited health education talks. Language \& Communication, 58, 80-92. https://doi.org/10.1016/j.langcom.2017.09.001

Tsai, M. H. (2003). Problems in identifying participant structures in medical triadic 
conversation. Journal of Taiwanese Languages and Literature, 1, 185-211.

Tsai, M. H. (2005). Opening stages in triadic medical encounters in Taiwan. Communication and Medicine, 2, 53-68. https://doi.org/10.1515/come.2005.2.1.53

Tsai, M. H. (2007). Who gets to talk? An alternative framework evaluating companion effects in geriatric triads. Communication and Medicine, 4, 37-49. https://doi.org/10.1515/cam.2007.005

Tsai, M. H. (2010). Managing topics of birth and death in doctor-patient communication. Journal of Pragmatics, 42, 1350-1363. https://doi.org/10.1016/j.pragma.2009.09.012

Tsai, M. H. (2017). 'Have you heard of diabetes?' The use of perspective-checking questions in creating knowledge needs in Taiwanese health education talks for elderly lay people. $\begin{array}{llll}\text { Concentric: } \quad \text { Studies } & \text { in }\end{array}$ https://doi.org/10.6241/concentric.ling.43.1.03

\section{Copyrights}

Copyright for this article is retained by the author(s), with first publication rights granted to the journal.

This is an open-access article distributed under the terms and conditions of the Creative Commons Attribution license (http://creativecommons.org/licenses/by/4.0/) 